Article

\title{
Polymeric Insulator Conditions Estimation by Using Leakage Current Characteristics Based on Simulation and Experimental Investigation
}

\author{
Ali Ahmed Salem ${ }^{1, *}$, Kwan Yiew Lau ${ }^{1, *(D)}$, Zulkurnain Abdul-Malek ${ }^{1}\left(\mathbb{D}\right.$, Nabil Mohammed $^{2}$ (D), \\ Abdullah M. Al-Shaalan ${ }^{3}$, Abdullrahman A. Al-Shamma'a ${ }^{3}$ (D) and Hassan M. H. Farh ${ }^{4}(\mathbb{D}$
}

check for

updates

Citation: Salem, A.A.; Lau, K.Y.; Abdul-Malek, Z.; Mohammed, N.; Al-Shaalan, A.M.; Al-Shamma'a, A.A.; Farh, H.M.H. Polymeric Insulator Conditions Estimation by Using Leakage Current

Characteristics Based on Simulation and Experimental Investigation. Polymers 2022, 14, 737. https:// doi.org/10.3390/polym14040737

Academic Editor: Sombel Diaham

Received: 29 December 2021

Accepted: 29 January 2022

Published: 14 February 2022

Publisher's Note: MDPI stays neutral with regard to jurisdictional claims in published maps and institutional affiliations.

Copyright: (C) 2022 by the authors. Licensee MDPI, Basel, Switzerland. This article is an open access article distributed under the terms and conditions of the Creative Commons Attribution (CC BY) license (https:// creativecommons.org/licenses/by/ $4.0 /)$.
1 Institute of High Voltage and High Current, School of Electrical Engineering, Universiti Teknologi Malaysia, Johor Bahru 81310, Malaysia; zulkurnain@utm.my

2 Department of Electrical and Computer Systems Engineering, Monash University, Wellington Rd., Clayton, VIC 3800, Australia; nabil.mohammed@ieee.org

3 Electrical Engineering Department, College of Engineering, King Saud University, Riyadh 11421, Saudi Arabia; shaalan@ksu.edu.sa (A.M.A.-S.); ashammaa@ksu.edu.sa (A.A.A.-S.)

4 Department of Building and Real Estate, Faculty of Construction and Environment, Hong Kong Polytechnic University, Hung Hom, Kowloon 999077, Hong Kong; hfarh.hussein@polyu.edu.hk

* Correspondence: ahmedali.a@utm.my (A.A.S.); kwanyiew@utm.my (K.Y.L.); Tel.: +60-185-734-853 (A.A.S.)

\begin{abstract}
The current work contributes an estimate of the time-frequency characteristics of a leakage current in assessing the health condition of a polluted polymeric insulator. A $33 \mathrm{kV}$ polymer insulator string was subjected to a series of laboratory tests under a range of environmental conditions, including pollution, wetting rate (WR), non-soluble deposit density (NSDD), and non-uniform distribution pollution $\left(\mathrm{F}_{\mathrm{T} / \mathrm{B}}\right)$. The temporal and frequency features of the leakage current were then extracted and used as assessment indicators for insulator conditions based on laboratory test findings. Two indices were generated from the leakage current waveform in the time domain: the curve slope index $\left(F_{1}\right)$, which is determined by measuring the inclination of the curve between two successive time peaks of the leakage current, and the crest factor indicator $\left(\mathrm{F}_{2}\right)$. The frequency domain of the leakage current signal was used to calculate the other two indices. These are the odd harmonic indicators derived from the odd frequency harmonics of the leakage current up to the 9 th component $\left(\mathrm{F}_{3}\right)$ and the 5 th to $3 \mathrm{rd}$ harmonics ratio $\left(\mathrm{F}_{4}\right)$. The findings showed that the suggested indicators were capable of evaluating insulator conditions. Finally, the confusion matrix for the experimental and prediction results obtained with the proposed indices was used to assess which indicator performed the best. Therefore, the analysis suggests an alternative and effective method for estimating the health condition of a polluted insulator through leakage current characteristics obtained in the time and frequency domains.
\end{abstract}

Keywords: polymer insulator; prediction; pollution; leakage current indices

\section{Introduction}

The insulator is one of the most significant components used in power transmission systems for holding and insulating electrical wires from towers. In this respect, it should be noted that several environmental elements, such as the kind of material, moisture, and the level of contaminants, have a significant impact on the efficacy of the outdoor insulator. Consequently, the continuation of pollutants deposited on the surface of insulators renders the insulators susceptible to significant leakage current flow. As a result, the insulator surface experiences widespread discharge activity [1-4]. These discharges can develop into an unwanted flashover that may disrupt an electrical grid [5-8]. Therefore, monitoring the condition of insulators has a significant effect on the power system stability $[9,10]$. The assessment of outdoor insulator properties and long-term efficiency is thus an important area of research in the science establishment [11-14]. 
The leakage current (LC) monitoring method has several advantages. It considers a variety of environmental factors such as ambient temperature, moisture, contamination, and rain [15]. Additionally, the leakage current may simply be checked online regularly. Leakage current computation and analysis, as one of the online tests performed for contaminated insulators, has piqued the interest of numerous researchers. The author of [16] has utilized a microwave-disapproved device to measure the LC on dry insulator surfaces. However, this technology is expensive and may be too expensive for low-cost power systems. The authors of [17] proposed a device that captures electromagnetic radiation from a partial discharge to monitor the leakage current of contaminated insulators. Although this system is not affected by flashover, it has not yet been tested in the field, where considerable electromagnetic interference caused by coronae and other effects on high voltage cables is expected. Moreover, another interesting aspect of the contaminated insulator LC tracking approach is the ability to create an effective correlation between the leakage current and the insulator status when the insulator is in operation. In this scenario, several academics have offered different approaches to assess the state of insulators [15,18-20]. By extracting information on the components of the LC, it is possible to improve LC-based monitoring. The authors of [21] proposed measuring the degree of contamination using LC summary statistics, which offer the mean, peak, and standard deviation values. They made it clear that these factors allow them to measure the size and density of contamination on the insulator surface. Another study [19] calculated insulator pollution conditions by monitoring the shift angle between the leakage current and applied voltage signals. As per the results in [19], shift angle alterations are a helpful signal for assessing contaminants and moisture variations between clean and dry settings. Other strategies may be used to anticipate insulators' pollutant incidence. This is only one of several approaches that have been developed in the field of insulators. Aside from that, a method known as leakage current component extraction, which has been used by various other studies [22-24], is a popular methodology that may assist in forecasting the pollution incidence of an insulator. In this procedure, the Fast Fourier Transform (FFT) and wavelet transform are employed to examine the leakage current signal in the frequency domain. Overall, the findings demonstrate that contamination on the insulator increases leakage current harmonic components, particularly the odd harmonics. Furthermore, the results indicate that pollution increases the 1st and 3rd harmonics as well as the total harmonic distortion (THD) [25]. According to the results in [26], the harmonics in question are the first and third components of an AC system with a frequency of $50 \mathrm{~Hz}$. Consequently, the study found that increasing these harmonics causes an increase in the total harmonic distortion (THD), which varies depending on the degree of pollution and applied voltage harmonics.

Recently, the pre-flashover circumstances of polymeric insulators under polluted environments were explored by utilizing a mix of analytical formulations based on the hybrid genetic algorithm and particle swarm optimization (HGA-PSO) method [26]. The results demonstrated that, under various pollution and pre-flashover scenarios, the relationship between the discharge resistance and the leakage current of experimental specimens were similar to those obtained through analytical formulations in the literature. There was a close connection between genuine experimental data, circuit analytical modeling from prior studies, and the HGA-PSO system. In [27], the time-frequency domain surface leakage current (SLC) signals of an $11 \mathrm{kV}$ polymeric insulator with a polluted surface were analyzed through hyperbolic window Stockwell transform (HST). The authors of [27] concluded that the suggested HST-based feature extraction approach could be used for polymeric insulator status monitoring.

It is highly advantageous to have an indicator that reflects the status of the insulators, as proposed in [15,19]. The authors of [28] used the basic assumption of the frequency components of the leakage current to construct the related indices throughout the context of this issue. When calculating flashover accidents, the indicator which determines the ratio of the 3rd to 5th harmonics of the leakage current and THD was used. The reported results for glass and polymeric insulators revealed a strong relationship between the extent of 
contamination and the reading of this indicator. Nonetheless, a literature survey revealed that no attempt had been made to compare the conditions of the insulators using different indices that take into account the time signal slope and frequency harmonics up to the 9 th component for the leakage current. Compared to the leakage current indicator ( $3 \mathrm{rd} / 5 \mathrm{th})$ proposed in [28], this approach is expected to produce a more dependable estimate.

The current work aimed to estimate the polymeric insulator condition under different environmental circumstances based on leakage current characteristics in the time and frequency domains extracted experimentally. To simulate the natural medium of insulators during service, the environmental parameters pollution level (SDD), wetting rate (WR), non-soluble deposit density (NSDD), and the non-uniform distribution of pollution $\left(\mathrm{F}_{\mathrm{T} / \mathrm{B}}\right)$ were taken into account. The results of the proposed leakage current indicators under the influence of environmental conditions were extracted experimentally. To assess the performance of these indicators, the confusion matrix for experimental data and prediction results using the suggested indices was employed.

\section{Materials and Methods}

\subsection{Test Sample}

The investigated polymer insulators were obtained from the "Transmission Division of Malaysian National Power (TNB)" in order to conduct the experiment. Figure 1 illustrates the main shape of the chosen insulator. Table 1 details the insulator's characteristics.

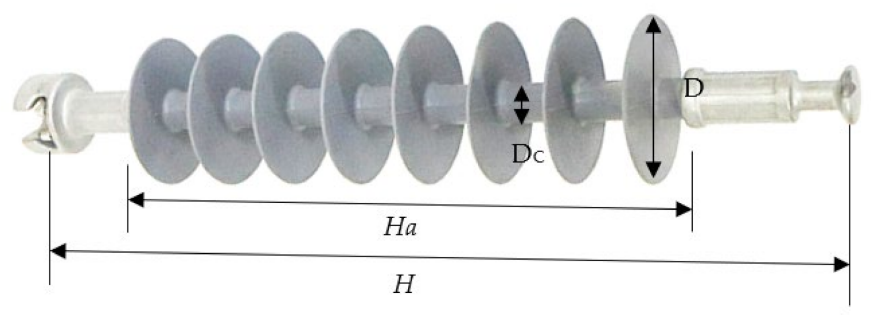

Figure 1. $33 \mathrm{kV}$ polymer insulator sample.

Table 1. Insulator parameters.

\begin{tabular}{ccc}
\hline Parameter & Symbol & Length $\mathbf{( c m )}$ \\
\hline Leakage distance & $\mathrm{L}_{\mathrm{t}}$ & 89 \\
Height & $\mathrm{H}$ & 52.5 \\
Diameter & $\mathrm{D}$ & 9.8 \\
Core diameter & $\mathrm{Dc}$ & 2.4 \\
Arc distance & $\mathrm{Ha}$ & 32.9 \\
\hline
\end{tabular}

\subsection{Experimental Setup}

This experimental setup follows the IEC 60507 standard [29]. All studies were carried out in a $50 \mathrm{~cm} \times 50 \mathrm{~cm} \times 75 \mathrm{~cm}$ polycarbonate sheet-walled artificial test chamber. Four inlets were constructed on the test chamber wall to soak the tested insulators. The high-voltage insulator experiment setup circuit diagram is demonstrated in Figure 2. The experiment circuit consists of a high-voltage single-phase transformer $(230 \mathrm{~V} / 100 \mathrm{kV}, 5 \mathrm{kVA}$, $50 \mathrm{~Hz})$, a capacitor divider (100:25,000 pf), a sample test inside the chamber, a leakage current monitoring system, a steam generator with a wetting rate controller, and a voltage divider (1000:1) by resistors used to measure the leakage current. 


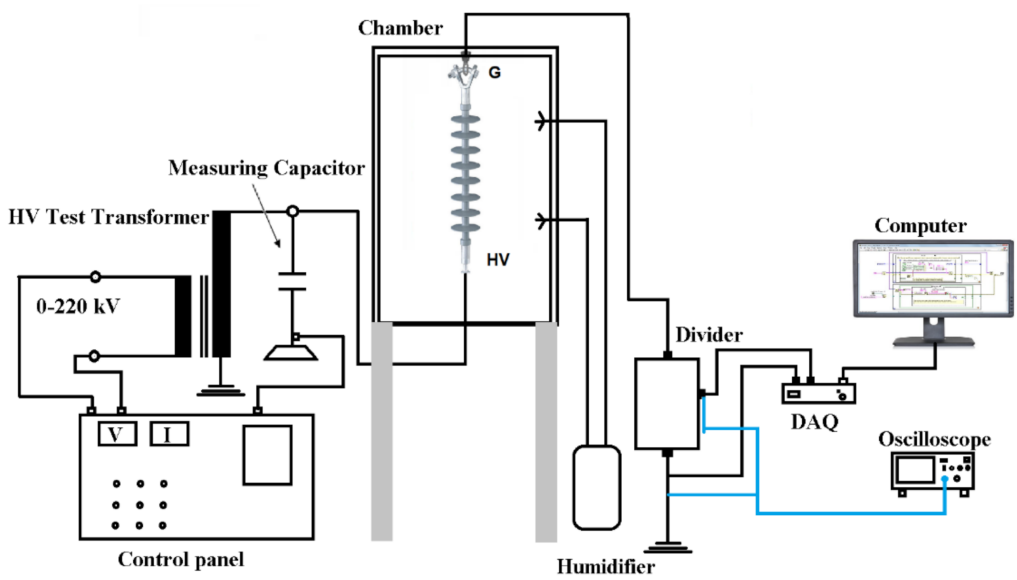

Figure 2. Experiment setup schematic diagram for the leakage current measurement of a polymeric insulator.

\subsection{Pollution and Wetting Process}

Before the test was carried out, alcohol was used to remove traces of grease and dirt from all specimens. After that, the insulator samples were naturally dried for 1 day. The pollutants were deposited on the surface of the insulator using the solid layer technique [30-33]. The sodium chloride salt $(\mathrm{NaCl})$ was used as Soluble Deposit Density (SDD) and the kaolin represents the Non-Soluble Deposit Density (NSDD). One liter of water was used to dissolve the sodium chloride salt and kaolin. To determine the SDD value, the electrical conductivity value of the contamination solution at room temperature was measured using a conductivity meter. The IEC 60507 standard [29] was followed to calculate SDD as in Equation (1):

$$
E S D D=\frac{\left(5.7 \times \sigma_{20}\right)^{1.03} \times V}{A}
$$

where $\sigma_{20}$ is the conductivity of the pollution solution at $20^{\circ} \mathrm{C}, V$ is the solution volume, and $A$ represents the area of the insulator surface. The NSDD is calculated using Equation (2):

$$
N S D D=\frac{\left[\left(w_{s}-w_{i}\right) \times 10^{3}\right]}{A}
$$

where $w_{S}$ and $w_{i}$ are the filter paper containing pollution in dry conditions. In this work, three levels of SSD and NSDD values were estimated corresponding to light, medium, and heavy pollution, as listed in Table 2 . The specimen was then contaminated and hung vertically on the artificial climate chamber handle, where the contaminated insulators were left to dry naturally for around $24 \mathrm{~h}$. During the experiment, the test room pressure was constant, the same as the laboratory's atmospheric pressure of $\sim 99.5 \mathrm{kPa}$. The test chamber temperature was around $28^{\circ} \mathrm{C}$, which would have been the indoor temperature as in Johor Town. The rain method was used in the wetting process. Eight slots distributed regularly in the chamber wall were used to wet the tested insulators. The flow rate of the fog was controlled by the control panel located outside the HV test room. This controller was utilized to adjust the flow rate of the water and air pressure, which help to control the wetting rate of the contaminated insulators. Three levels of wetting rates were chosen: $31 / h, 61 / h$, and $91 / h$, which were used to simulate the wetting of insulators in various climates. 
Table 2. Pollution layer components.

\begin{tabular}{ccccc}
\hline Parameters & \multicolumn{4}{c}{ Values } \\
\hline Pollution level & Clean $(\mathrm{C})$ & Light $(\mathrm{L})$ & Medium $(\mathrm{M})$ & Heavy $(\mathrm{H})$ \\
ESDD $\left(\mathrm{mg} / \mathrm{cm}^{2}\right)$ & 0.0 & 0.05 & 0.10 & 0.15 \\
NSDD $\left(\mathrm{mg} / \mathrm{cm}^{2}\right)$ & 0.0 & 0.3 & 0.6 & 0.9 \\
Wetting rate $(\mathrm{l} / \mathrm{h})$ & 0.0 & 3 & 6 & 9 \\
\hline
\end{tabular}

The polymer insulator was tested under uniform and nonuniform pollution distribution. In non-uniform pollution, three different pollution ratios of the upper to the lower side of $\operatorname{ESDD}\left(\mathrm{F}_{\mathrm{T} / \mathrm{B}}\right)$ were chosen to be 1/5,1/10, and 1/15. During the nonuniform application of contamination, the upper and bottom surfaces of the insulator are contaminated separately to obtain $\mathrm{SDD}_{\mathrm{T}}$ and $\mathrm{SDD}_{\mathrm{B}}$, while the overall $\mathrm{SDD}$ can be fulfilled by $[5,34,35]$ :

$$
E S D D=\frac{S D D_{T} \times A_{T}+S D D_{B} \times A_{B}}{A_{T}+A_{B}}
$$

where $A_{T}$ and $A_{B}$ are the areas of the top and bottom surfaces of the insulator, respectively.

\subsection{Monitoring of Data}

Referring to the experimental setup in Figure 2, the applied voltage was measured using a capacitive divider voltage and oscilloscope in the control panel. For the leakage current, the monitoring system of the LC consists of a DAQ card, PC, and oscilloscope. Because the allowable input voltage range of $\mathrm{DAQ}$ is $\pm 10 \mathrm{~V}$, a downscaling voltage divider $(10,000: 1)$ was used. Data were transferred from the DAQ to a PC, then saved as a CSV file, and displayed on a LabVIEW graphical user interface. For correct measurements, the oscilloscope was also used to verify the DAQ reading of data. The leakage current data stored were analyzed in the frequency domain using MATLAB software.

\subsection{Leakage Current Features}

One way to develop new tools for diagnosing the safety state of contaminated insulators is to extract advantageous features from leakage current data. The frequency domain and time domain of the LC signal may be used to obtain these features. In this research, four indices for leakage current are recovered in both the temporal and frequency domains. Figure 3 depicts the insulator condition diagnostic procedure utilizing leakage current features.

Indicators for insulator states were derived from leakage current characteristics in time and frequency domains. The slope of the line connecting two successive peaks of the leakage current signal was used to calculate the first indicator, $\mathrm{F}_{1}$. The second indicator, $\mathrm{F}_{2}$, is based on the crest factor, which was computed by dividing the peak to RMS ratio of the leakage current waveforms by two. The third, $\mathrm{F}_{3}$, and fourth, $\mathrm{F}_{4}$, indicators were determined by utilizing the odd harmonics of the leakage current under $500 \mathrm{~Hz}$. The proposed indicators were expressed as follows:

$$
\begin{gathered}
F_{1}=\frac{\sum_{n=1}^{m}\left|y_{n}-y_{n-1}\right|}{x_{n}-x_{n-1}}=\frac{\sum_{0}^{m}\left|\Delta y_{n}\right|}{\Delta x_{n}} \\
F_{2}=\frac{I_{\text {peak }}}{I_{R M S}} \\
F_{3}=\frac{\sum_{n} I_{n}}{I_{3}} \quad n=5,7,9 \\
F_{4}=\frac{I_{5}}{I_{3}}
\end{gathered}
$$


where $\Delta y_{n}$ represents the difference in the leakage current between adjacent peaks at the $n^{\text {th }}$ point of time, $\Delta x_{n}$ represents the time between these peaks, $I_{\text {peak }}$ is the peak value of the leakage current, $I_{R M S}$ is the root mean square of the leakage current, $I_{3}$ is the third harmonic of the leakage current, $I_{5}$ is the fifth harmonic of the leakage current, $I_{n}$ is the $n^{\text {th }}$ order harmonic, and $n$ represents the odd-order harmonic numbers. Figure 4 depicts the leakage current characteristics in the time and frequency signals used to calculate the proposed indicators.



Figure 3. Insulator condition diagnosis using leakage current characteristics flowchart.

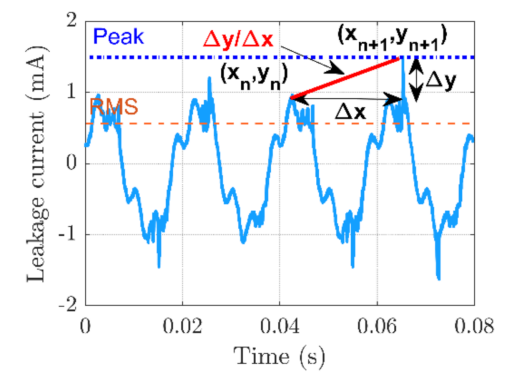

(a)



(b)

Figure 4. Leakage current features (a), time domain for extract indicators 1 and $2\left(F_{1}\right.$ and $\left.F_{2}\right)(b)$, leakage current frequency domain for extract indicator $3 \mathrm{~F}_{3}$.

\section{Results and Analysis}

\subsection{Leakage Current Findings}

The leakage current waveform in the time domain was measured and converted to FFT using MATLAB software. Some leakage current results in time and frequency domains under different uniform pollutions, $0.15 \mathrm{mg} / \mathrm{cm}^{2}$ of NSDD, and $31 / \mathrm{h}$ of wetting rate are depicted in Figure 5. 


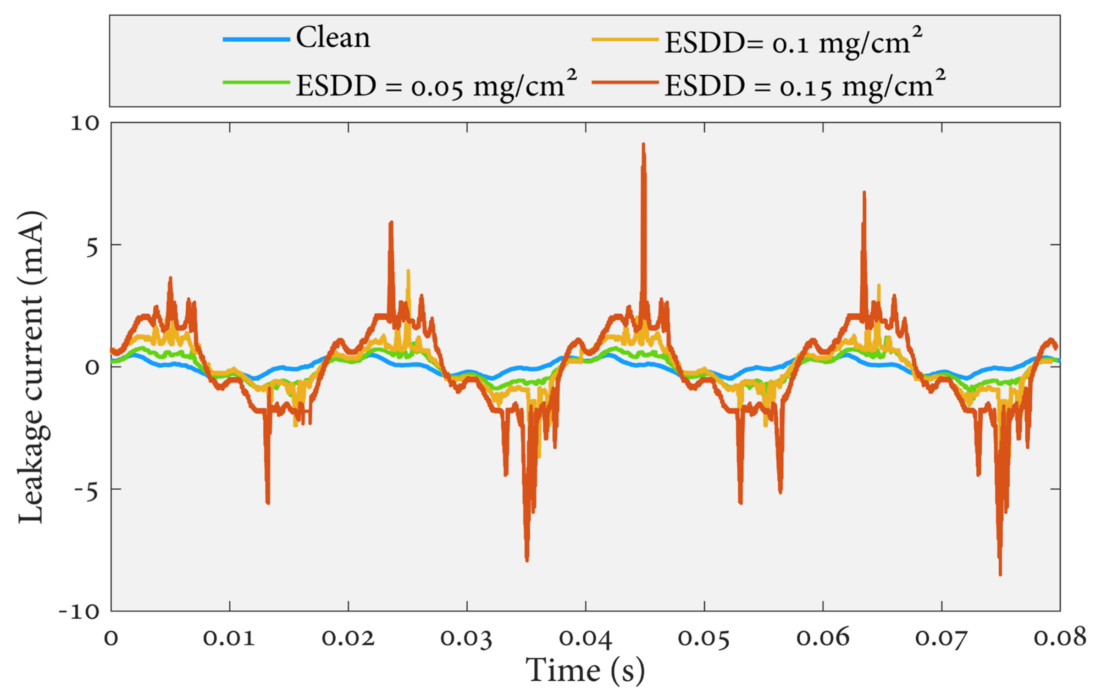

(a)

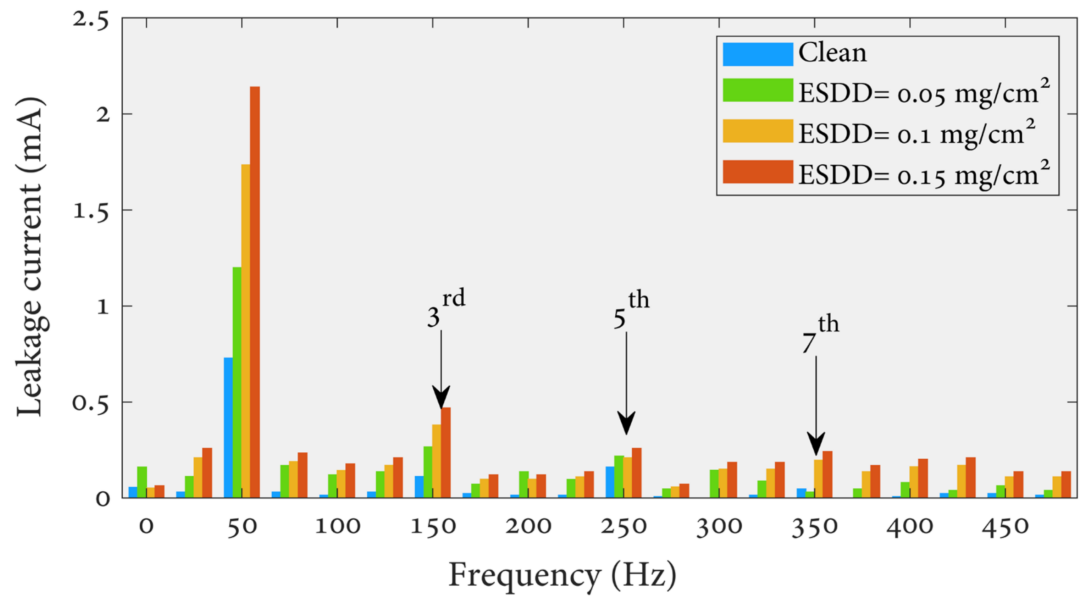

(b)

Figure 5. Leakage current signal under different contamination levels, 0.15 of NSDD, and $31 / \mathrm{h}$ of wetting rate: (a) time waveform; (b) FFT.

Figure 5 shows a significant increase in the leakage current due to increased pollution severity under certain NSDD, wetting rate, and $\mathrm{F}_{\mathrm{T} / \mathrm{B}}$. The possible explanation for the current rising is the formation of a film due to pollution and wetness, which increases the conductivity along the surface of the insulator. As a result, an easy path was produced for the flow current in the form of positively and negatively charged ions between insulator electrodes. Under heavy pollution conditions, occasional spot-arcing was observed, especially in the presence of wetness. When the arcing was occurring, the leakage current signal became severely warped. Meanwhile, an increase in the leakage current was followed by an increase in the harmonic values. On the other hand, a significant difference in the components (3rd, 5th, 7th, and 9th) can be noticed when increasing the pollution degree on the surfaces of the insulators. The 3rd harmonic will rise to exceed the 5 th, 7 th, and 9th, with an apparent increase in the 7th and 9th, as reported in Figure 6. Furthermore, during arcing activity on the surface of the insulator, the third harmonic component is often considerably high [36]. 


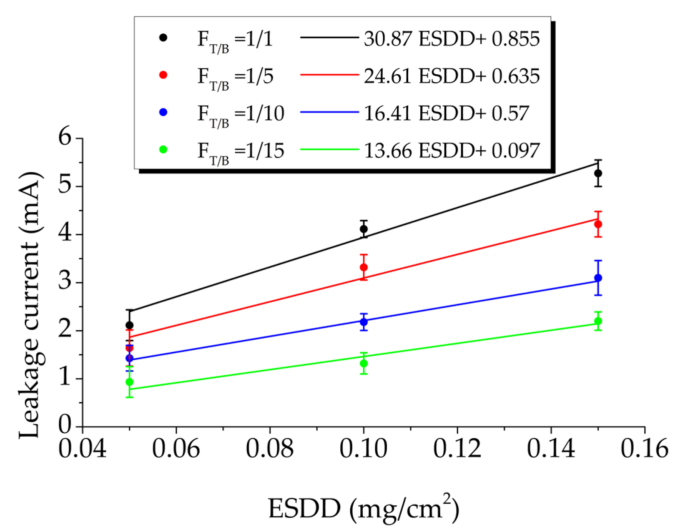

(a)

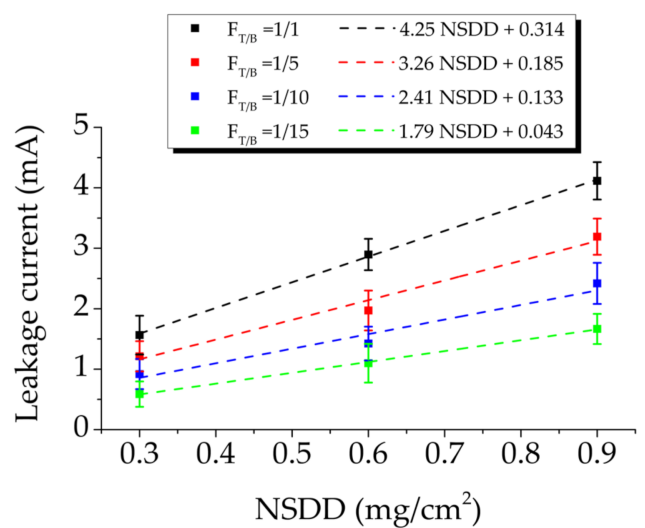

(b)

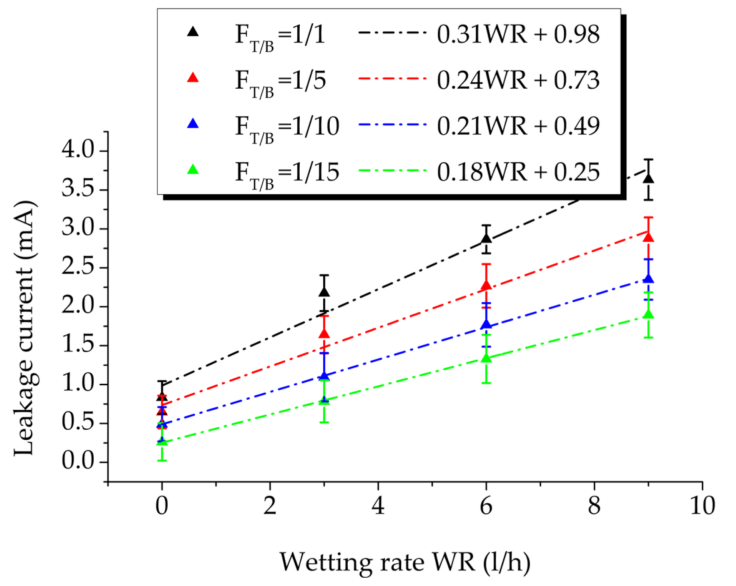

(c)

Figure 6. Leakage current under different values of $\mathrm{F}_{\mathrm{T} / \mathrm{B}}$. (a) Relationship between leakage current and ESDD when NSDD $=0.9\left(\mathrm{mg} / \mathrm{cm}^{2}\right)$ and $\mathrm{WR}=9(\mathrm{l} / \mathrm{h}) ;(\mathrm{b})$ relationship between leakage current and NSDD when ESDD $=0.1\left(\mathrm{mg} / \mathrm{cm}^{2}\right)$ and $\mathrm{WR}=9(\mathrm{l} / \mathrm{h}) ;(\mathrm{c})$ relationship between leakage current and ESDD when ESDD $=0.15\left(\mathrm{mg} / \mathrm{cm}^{2}\right)$ and NSDD $=0.9(\mathrm{l} / \mathrm{h})$.

Table 3 illustrates the measured leakage current components values under uniform contamination for all conditions proposed in Table 1. The experimental results showed no signs of a flashover in clean and light pollution conditions. The leakage current increased slightly as the wetting rate increased when the clean insulators were tested under different wetting conditions. This means that wetting on the insulator surface has a noticeable ability to raise the flow charges from the HV electrode to the ground electrode.

According to Table 3, the leakage current value on a clean surface of the insulator is minimal, around $0.183 \mathrm{~mA}$, and predominantly capacitive, with a phase change angle of about $90^{\circ}$. In a clean and dry scenario, the fifth harmonic component is always greater than the third component. Figure 6 shows the leakage current results of the polluted insulator with the change of the uneven contamination $\left(\mathrm{F}_{\mathrm{T} / \mathrm{B}}\right)$, equivalate soluble deposit density (ESDD), wetting rate (WR), and non-soluble deposit density (NSDD). Overall, it can be seen from test data in Figure 6 that the leakage current is expected to grow substantially as the pollution levels (ESDD), NSDD, and wetting rate rise. Variations in leakage current amplitude increased as the ESDD, NSDD, and WR increased and $\mathrm{Pu} / \mathrm{Pl}$ decreased. In dry conditions, surface conductivity is thought to be at its lowest. Accordingly, the effect of increasing the ESDD and NSDD on leakage current and its components under dry conditions was also slight. The linear fit was utilized to estimate the association between leakage current and SDD, NSSD, and the wetting rate at various $\left(\mathrm{F}_{\mathrm{T} / \mathrm{B}}\right)$ values (Figure 6). The slope and intercept of linear model details are shown in Figure 7. 
Table 3. Leakage current components under uniform conditions.

\begin{tabular}{|c|c|c|c|c|c|c|c|}
\hline ESDD & NSDD & WR & $I_{1}$ & $I_{3}$ & $\mathbf{I}_{5}$ & $I_{7}$ & $I_{9}$ \\
\hline \multirow{13}{*}{0.00} & 0 & 0 & 0.1483 & 0.0004 & 0.0016 & 0.0000 & 0.0016 \\
\hline & \multirow{4}{*}{0.3} & 0 & 0.1621 & 0.0005 & 0.0024 & 0.0008 & 0.0004 \\
\hline & & 3 & 0.3566 & 0.0024 & 0.0122 & 0.0016 & 0.0006 \\
\hline & & 6 & 0.5835 & 0.0032 & 0.0103 & 0.0065 & 0.0006 \\
\hline & & 9 & 0.7293 & 0.0057 & 0.0138 & 0.0081 & 0.0049 \\
\hline & \multirow{4}{*}{0.6} & 0 & 0.1783 & 0.0024 & 0.0113 & 0.0016 & 0.0016 \\
\hline & & 3 & 0.5429 & 0.0081 & 0.0332 & 0.0041 & 0.0049 \\
\hline & & 6 & 0.7050 & 0.0088 & 0.0324 & 0.0065 & 0.0057 \\
\hline & & 9 & 0.7861 & 0.0138 & 0.0486 & 0.0081 & 0.0065 \\
\hline & \multirow{4}{*}{0.9} & 0 & 0.3323 & 0.0047 & 0.0097 & 0.0073 & 0.0073 \\
\hline & & 3 & 0.5997 & 0.0146 & 0.0486 & 0.0041 & 0.0024 \\
\hline & & 6 & 0.7374 & 0.0162 & 0.0515 & 0.0049 & 0.0041 \\
\hline & & 9 & 0.8509 & 0.0267 & 0.0592 & 0.0057 & 0.0073 \\
\hline \multirow{12}{*}{0.05} & \multirow{4}{*}{0.3} & 0 & 0.4230 & 0.0073 & 0.0348 & 0.0073 & 0.0032 \\
\hline & & 3 & 0.7293 & 0.1013 & 0.2593 & 0.0486 & 0.0243 \\
\hline & & 6 & 0.9643 & 0.1102 & 0.2431 & 0.0673 & 0.0324 \\
\hline & & 9 & 1.2723 & 0.1459 & 0.2917 & 0.0746 & 0.0624 \\
\hline & \multirow{4}{*}{0.6} & 0 & 0.5916 & 0.0113 & 0.0454 & 0.0065 & 0.0057 \\
\hline & & 3 & 0.9968 & 0.1151 & 0.1872 & 0.0689 & 0.0535 \\
\hline & & 6 & 1.2075 & 0.1353 & 0.1864 & 0.1135 & 0.0567 \\
\hline & & 9 & 1.4911 & 0.1451 & 0.1872 & 0.1216 & 0.0648 \\
\hline & \multirow{4}{*}{0.9} & 0 & 0.7374 & 0.0146 & 0.0527 & 0.0105 & 0.0081 \\
\hline & & 3 & 1.3209 & 0.1540 & 0.2042 & 0.0827 & 0.0454 \\
\hline & & 6 & 1.6532 & 0.1783 & 0.1945 & 0.1135 & 0.0729 \\
\hline & & 9 & 2.1151 & 0.2115 & 0.2593 & 0.0972 & 0.0891 \\
\hline \multirow{12}{*}{0.10} & \multirow{4}{*}{0.3} & 0 & 0.5154 & 0.0178 & 0.0583 & 0.0089 & 0.0065 \\
\hline & & 3 & 1.1994 & 0.2674 & 0.2188 & 0.0324 & 0.0648 \\
\hline & & 6 & 1.3209 & 0.3323 & 0.2593 & 0.0502 & 0.0972 \\
\hline & & 9 & 1.5640 & 0.3728 & 0.3323 & 0.0770 & 0.0648 \\
\hline & \multirow{4}{*}{0.6} & 0 & 0.6078 & 0.0259 & 0.0681 & 0.0105 & 0.0170 \\
\hline & & 3 & 1.3938 & 0.2836 & 0.2512 & 0.0843 & 0.0729 \\
\hline & & 6 & 1.5883 & 0.4295 & 0.2998 & 0.0891 & 0.0794 \\
\hline & & 9 & 1.8963 & 0.4619 & 0.3323 & 0.1053 & 0.0891 \\
\hline & \multirow{4}{*}{0.9} & 0 & 0.7618 & 0.0332 & 0.0713 & 0.0251 & 0.0186 \\
\hline & & 3 & 1.6045 & 0.4538 & 0.2917 & 0.1053 & 0.1297 \\
\hline & & 6 & 1.6532 & 0.5835 & 0.3323 & 0.1216 & 0.1053 \\
\hline & & 9 & 2.1151 & 0.5024 & 0.3404 & 0.1378 & 0.1459 \\
\hline \multirow{12}{*}{0.15} & \multirow{4}{*}{0.3} & 0 & 0.6823 & 0.0429 & 0.0778 & 0.0365 & 0.0259 \\
\hline & & 3 & 2.1394 & 0.7780 & 0.2269 & 0.1702 & 0.1216 \\
\hline & & 6 & 2.3825 & 0.8023 & 0.1864 & 0.2107 & 0.0891 \\
\hline & & 9 & 2.9579 & 0.8809 & 0.1864 & 0.2188 & 0.1053 \\
\hline & \multirow{4}{*}{0.6} & 0 & 0.8347 & 0.0502 & 0.0810 & 0.0511 & 0.0259 \\
\hline & & 3 & 2.3744 & 0.7699 & 0.2269 & 0.1702 & 0.0891 \\
\hline & & 6 & 2.6661 & 0.8833 & 0.2188 & 0.1864 & 0.0972 \\
\hline & & 9 & 3.2334 & 1.0535 & 0.2593 & 0.1945 & 0.0972 \\
\hline & \multirow{4}{*}{0.9} & 0 & 0.8671 & 0.0527 & 0.0827 & 0.0389 & 0.0405 \\
\hline & & 3 & 2.8687 & 1.1280 & 0.2431 & 0.0972 & 0.1216 \\
\hline & & 6 & 4.2464 & 1.3128 & 0.2836 & 0.1702 & 0.0972 \\
\hline & & 9 & 5.2755 & 1.4506 & 0.2188 & 0.1053 & 0.1378 \\
\hline
\end{tabular}




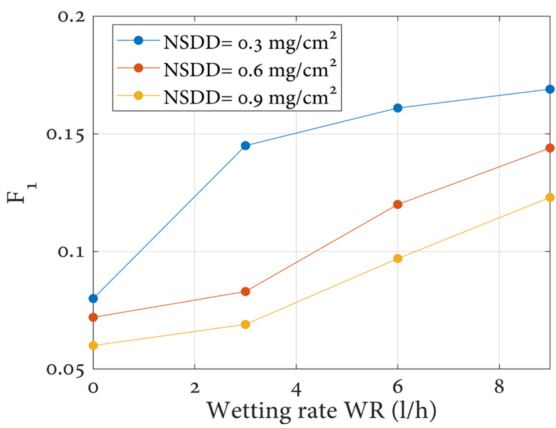

(a)

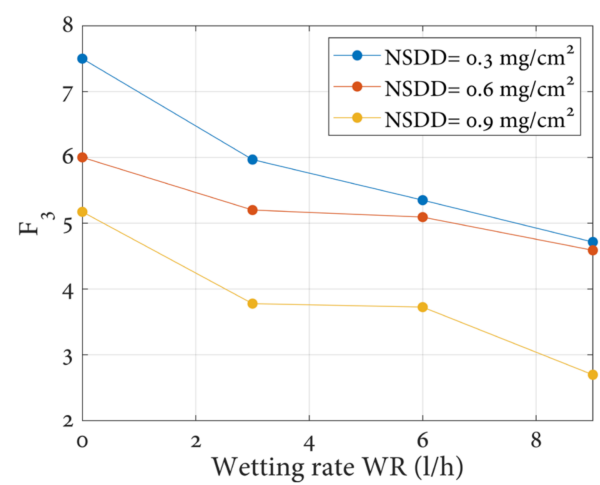

(c)

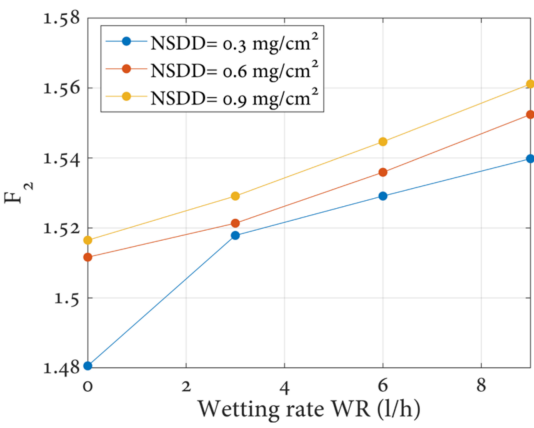

(b)

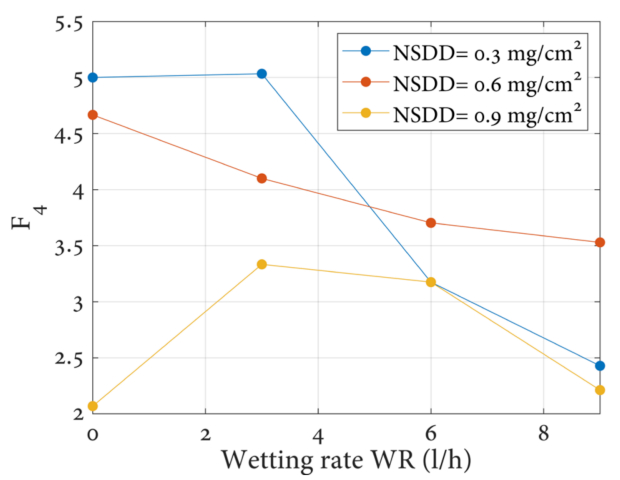

(d)

Figure 7. Leakage current indices of clean insulators under various wetting rates WR and NSDD: (a) indicator $1, \mathrm{~F}_{1} ;(\mathbf{b})$ indicator $2, \mathrm{~F}_{2} ;(\mathbf{c})$ indicator $3, \mathrm{~F}_{3} ;(\mathrm{d})$ indicator $4, \mathrm{~F}_{4}$.

\subsection{Leakage Current Indicators Results}

As previously stated, the leakage current value changes slightly as the wetting rate changes under clean conditions; similarly, the time and frequency characteristics of the leakage current will change. Figure 7 shows the leakage current indices of the clean insulator under different wetting rates. Each indicator has a special behavior when changing the wetting rate and NSDD. According to Figure 7, it can be concluded that:

(1) With an NSDD change at the same wetting rate, WR, there is a considerable influence on the presented indicators.

(2) The $F_{1}$ and $F_{2}$ indices increase with the increase of both the wetting rate and NSDD. It can be seen that when the WR increases from $31 / \mathrm{h}$ to $91 / \mathrm{h}$ under a certain NSDD of $0.3 \mathrm{mg} / \mathrm{cm}^{2}$, the $F_{1}$ increases from 0.08 to 0.17 and $F_{2}$ increases from 1.516 to 1.56 .

(3) The $\mathrm{F}_{3}$ and $\mathrm{F}_{4}$ decrease with the increase of both wetting rate, WR, and NSDD. It can be observed that when the WR increases from $31 / \mathrm{h}$ to $91 / \mathrm{h}$ under a certain NSDD of $0.3 \mathrm{mg} / \mathrm{cm}^{2}$, the $\mathrm{F}_{2}$ decreases from 7.51 to 4.74 and $\mathrm{F}_{4}$ decreases from 5.09 to 2.47.

(4) At a particular wetting rate, the $\mathrm{F}_{4}$ is strongly impacted by harmonics in the leakage current waveform and becomes inaccurate as a monitoring indication, as seen in Figure $8 \mathrm{~d}$. In comparison, while the $\mathrm{F}_{1}, \mathrm{~F}_{2}$, and $\mathrm{F}_{3}$ remain fairly stable under constant wetting rate regardless of harmonics in the leakage current signal, increasing the wetting rate causes an increase in the $F_{1}$ and $F_{2}$ and a decrease in the $F_{3}$, making them more reliable indices for monitoring the insulator state than the $\mathrm{F}_{4}$. 


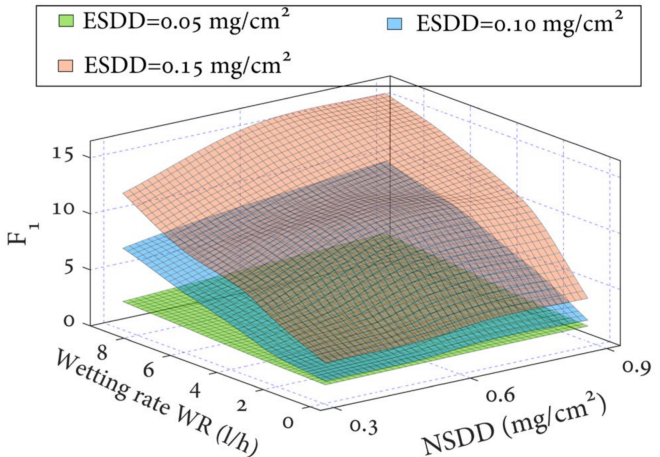

(a)

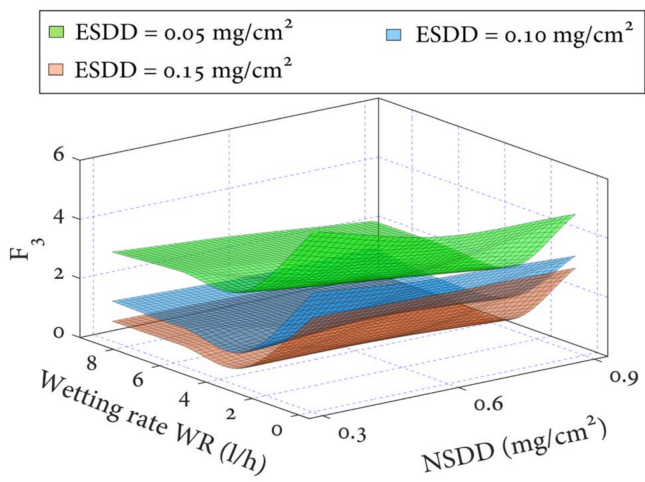

(c)

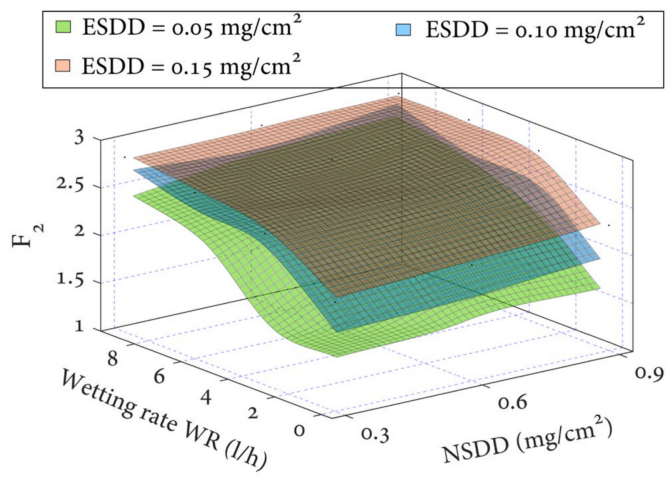

(b)

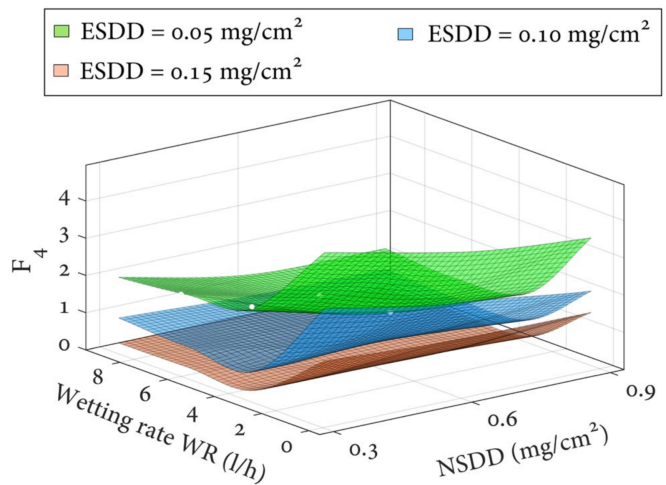

(d)

Figure 8. Proposed indices of uniform polluted insulators under different wetting rates, WR, and NSDD: (a) indicator $1, \mathrm{~F}_{1} ;(\mathbf{b})$ indicator $2, \mathrm{~F}_{2} ;(\mathbf{c})$ indicator $3, \mathrm{~F}_{3} ;(\mathbf{d})$ indicator $4, \mathrm{~F}_{4}$.

\subsection{Indices Trend under the Effect of Pollution Components}

The leakage current indicators were studied at various levels of the pollution layer components listed in Table 2 (ESDD, NSDD, $\mathrm{WR}$, and $\mathrm{F}_{\mathrm{T} / \mathrm{B}}$ ). Figure 8 and Table 4 demonstrate that the leakage current indices $F_{1}$ and $F_{2}$ of the investigated insulators rise with increasing $\mathrm{SDD}, \mathrm{WR}$, and $\mathrm{F}_{\mathrm{T} / \mathrm{B}}$. Under the same conditions, however, the insulator indices $\mathrm{F}_{3}$ and $\mathrm{F}_{2}$ decrease as the SDD increases. For instance, when the NSDD $=0.6 \mathrm{mg} / \mathrm{cm}^{2}$, $\mathrm{WR}=61 / \mathrm{h}$, and $\mathrm{F}_{\mathrm{T} / \mathrm{B}}=1$, the $\mathrm{F}_{1}$ value is $1.09,6.93$, and $11.46 \mathrm{~mA}$ whenever ESDD is 0.05 , 0.10 , and $0.15 \mathrm{mg} / \mathrm{cm}^{2}$, respectively. It can be seen that when the ESDD is raised from 0.05 to 0.12 and $0.2 \mathrm{mg} / \mathrm{cm}^{2}$, the $\mathrm{F}_{1}$ increases by $84.17 \%$ and $90.4 \%$, respectively. Whereas, when the ESDD is $0.05,0.12$, and $0.2 \mathrm{mg} / \mathrm{cm}^{2}$, the corresponding $\mathrm{F}_{3}$ is $2.99,1.24$, and $0.64 \mathrm{~mA}$, respectively. It can be noted that the $\mathrm{F}_{1}$ decreases by $58.6 \%$ and $48.83 \%$, respectively. The results show that the indicator $F_{1}$ changes significantly at high ESDD levels. The slopes of the $\mathrm{F}_{2}, \mathrm{~F}_{3}$, and $\mathrm{F}_{4}$ values are identical across the three ESDD levels.

Variations in the indices are similar to the previous situation with pollution variation. The test results in Table 4 show that for constant ESDD, WR, and $\mathrm{F}_{\mathrm{T} / \mathrm{B}}$, if the NSDD increases, the $F_{1}$ and $F_{2}$ will increase while the $F_{3}$ and $F_{4}$ will decrease. Figure 9 a depicts the $F_{1}-F_{4}$ versus NSDD curves for $\mathrm{ESDD}=0.15 \mathrm{mg} / \mathrm{cm}^{2}, \mathrm{WR}=6 \mathrm{l} / \mathrm{h}$, and $\mathrm{F}_{\mathrm{T} / \mathrm{B}}=1 / 1$ to help explain the association between NSDD and the proposed indices. The relationship between the proposed indices F1-F4 and the wetting rate, WR, for a polymer insulator under $\mathrm{ESDD}=0.15 \mathrm{mg} / \mathrm{cm}^{2}, \mathrm{NSDD}=0.9 \mathrm{mg} / \mathrm{cm}^{2}$, and $\mathrm{F}_{\mathrm{T} / \mathrm{B}}=1 / 1$ and different wetting rates, WR, is shown in Figure $9 b$. 
Table 4. Leakage current indicators of polymer insulators under variation non-uniform pollution $\mathrm{F}_{\mathrm{T} / \mathrm{B}}$, wetting rate (WR), and NSDD.

\begin{tabular}{|c|c|c|c|c|c|c|c|c|c|c|c|c|c|c|}
\hline \multicolumn{3}{|c|}{$\mathbf{F}_{\mathrm{T} / \mathrm{B}}$} & \multicolumn{4}{|c|}{$1 / 5$} & \multicolumn{4}{|c|}{$1 / 10$} & \multicolumn{4}{|c|}{$1 / 15$} \\
\hline $\begin{array}{l}\text { ESDD } \\
\mathrm{mg} / \mathrm{cm}^{2}\end{array}$ & $\begin{array}{l}\text { NSDD } \\
\mathrm{mg} / \mathrm{cm}^{2}\end{array}$ & $\begin{array}{l}W_{t} \\
1 / h\end{array}$ & $\mathbf{F}_{1}$ & $F_{2}$ & $F_{3}$ & $\mathbf{F}_{4}$ & $F_{1}$ & $F_{2}$ & $\mathbf{F}_{3}$ & $\mathbf{F}_{4}$ & $F_{1}$ & $F_{2}$ & $F_{3}$ & $F_{4}$ \\
\hline \multirow{12}{*}{0.05} & \multirow{4}{*}{0.3} & 0 & 0.11 & 1.18 & 7.92 & 6.14 & 0.08 & 0.81 & 5.45 & 4.23 & 0.05 & 0.47 & 8.32 & 6.26 \\
\hline & & 3 & 0.30 & 1.26 & 3.89 & 2.68 & 0.21 & 0.87 & 2.68 & 1.84 & 0.14 & 0.51 & 4.09 & 2.73 \\
\hline & & 6 & 0.64 & 1.29 & 3.62 & 2.28 & 0.44 & 0.89 & 2.49 & 1.57 & 0.30 & 0.52 & 3.80 & 2.33 \\
\hline & & 9 & 0.85 & 1.30 & 3.46 & 2.08 & 0.58 & 0.89 & 2.38 & 1.43 & 0.39 & 0.52 & 3.64 & 2.12 \\
\hline & \multirow{4}{*}{0.6} & 0 & 0.25 & 1.31 & 7.78 & 6.60 & 0.17 & 0.90 & 5.35 & 4.54 & 0.12 & 0.53 & 8.18 & 6.73 \\
\hline & & 3 & 0.57 & 1.28 & 3.21 & 1.97 & 0.39 & 0.88 & 2.21 & 1.36 & 0.26 & 0.51 & 3.37 & 2.01 \\
\hline & & 6 & 0.89 & 1.29 & 3.06 & 1.92 & 0.61 & 0.89 & 2.11 & 1.32 & 0.41 & 0.52 & 3.22 & 1.96 \\
\hline & & 9 & 2.56 & 1.30 & 3.04 & 1.97 & 1.76 & 0.89 & 2.09 & 1.36 & 1.19 & 0.52 & 3.19 & 2.01 \\
\hline & \multirow{4}{*}{0.9} & 0 & 0.43 & 1.32 & 7.12 & 5.31 & 0.30 & 0.91 & 4.90 & 3.65 & 0.20 & 0.53 & 7.48 & 5.42 \\
\hline & & 3 & 0.72 & 1.29 & 2.48 & 1.55 & 0.50 & 0.89 & 1.71 & 1.07 & 0.33 & 0.52 & 2.61 & 1.58 \\
\hline & & 6 & 2.51 & 1.30 & 2.50 & 1.26 & 1.73 & 0.89 & 1.72 & 0.87 & 1.16 & 0.52 & 2.63 & 1.29 \\
\hline & & 9 & 4.66 & 1.31 & 2.41 & 1.26 & 3.21 & 0.90 & 1.66 & 0.87 & 2.16 & 0.53 & 2.53 & 1.29 \\
\hline \multirow{12}{*}{0.10} & \multirow{4}{*}{0.3} & 0 & 0.52 & 1.33 & 6.07 & 4.85 & 0.36 & 0.92 & 4.18 & 3.34 & 0.24 & 0.53 & 6.38 & 4.95 \\
\hline & & 3 & 1.87 & 1.27 & 1.48 & 1.08 & 1.29 & 0.87 & 1.02 & 0.74 & 0.87 & 0.51 & 1.56 & 1.10 \\
\hline & & 6 & 3.89 & 1.31 & 1.51 & 0.96 & 2.68 & 0.90 & 1.04 & 0.66 & 1.80 & 0.53 & 1.59 & 0.98 \\
\hline & & 9 & 6.70 & 1.84 & 1.68 & 1.17 & 3.23 & 1.27 & 1.16 & 0.81 & 2.18 & 0.74 & 1.77 & 1.19 \\
\hline & \multirow{4}{*}{0.6} & 0 & 0.65 & 2.00 & 5.76 & 4.31 & 0.45 & 1.38 & 3.96 & 2.97 & 0.30 & 0.80 & 6.05 & 4.40 \\
\hline & & 3 & 4.66 & 1.33 & 1.64 & 1.02 & 3.21 & 0.92 & 1.13 & 0.70 & 2.16 & 0.53 & 1.72 & 1.04 \\
\hline & & 6 & 5.59 & 1.80 & 1.49 & 0.95 & 3.85 & 1.24 & 1.03 & 0.65 & 2.59 & 0.72 & 1.57 & 0.97 \\
\hline & & 9 & 7.11 & 2.00 & 1.49 & 0.95 & 4.89 & 1.38 & 1.03 & 0.65 & 3.30 & 0.80 & 1.57 & 0.97 \\
\hline & \multirow{4}{*}{0.9} & 0 & 0.66 & 2.14 & 4.74 & 2.96 & 0.45 & 1.47 & 3.26 & 2.04 & 0.31 & 0.86 & 4.98 & 3.02 \\
\hline & & 3 & 4.27 & 1.34 & 1.32 & 0.81 & 2.94 & 0.92 & 0.91 & 0.56 & 1.98 & 0.54 & 1.39 & 0.83 \\
\hline & & 6 & 6.08 & 1.83 & 1.32 & 0.79 & 4.18 & 1.26 & 0.91 & 0.54 & 2.82 & 0.73 & 1.39 & 0.81 \\
\hline & & 9 & 8.57 & 2.06 & 1.36 & 0.79 & 5.90 & 1.42 & 0.94 & 0.54 & 3.97 & 0.83 & 1.43 & 0.81 \\
\hline \multirow{12}{*}{0.15} & \multirow{5}{*}{0.3} & 0 & 0.85 & 2.19 & 3.90 & 2.18 & 0.58 & 1.51 & 2.68 & 1.50 & 0.39 & 0.88 & 4.10 & 2.22 \\
\hline & & 3 & 4.87 & 1.46 & 0.77 & 0.21 & 3.35 & 1.00 & 0.53 & 0.14 & 2.26 & 0.59 & 0.81 & 0.21 \\
\hline & & 6 & 6.32 & 1.97 & 0.72 & 0.27 & 4.35 & 1.36 & 0.50 & 0.19 & 2.93 & 0.79 & 0.76 & 0.28 \\
\hline & & 9 & 9.33 & 2.08 & 0.68 & 0.27 & 5.04 & 1.43 & 0.47 & 0.19 & 3.40 & 0.83 & 0.71 & 0.28 \\
\hline & & 0 & 1.05 & 2.24 & 3.74 & 1.94 & 0.72 & 1.54 & 2.57 & 1.34 & 0.49 & 0.90 & 3.93 & 1.98 \\
\hline & \multirow{3}{*}{0.6} & 3 & 7.92 & 1.50 & 0.80 & 0.35 & $5.4 \overline{5}$ & 1.03 & 0.55 & 0.24 & 3.67 & 0.60 & 0.84 & 0.36 \\
\hline & & 6 & 9.25 & 2.03 & 0.71 & 0.30 & 6.37 & 1.40 & 0.49 & 0.21 & 4.29 & 0.81 & 0.75 & 0.31 \\
\hline & & 9 & 12.46 & 2.05 & 0.61 & 0.37 & 8.58 & 1.41 & 0.42 & 0.25 & 5.78 & 0.82 & 0.64 & 0.38 \\
\hline & \multirow{4}{*}{0.9} & 0 & 0.52 & 2.18 & 3.65 & 1.88 & 0.36 & 1.50 & 2.51 & 1.29 & 0.24 & 0.87 & 3.84 & 1.92 \\
\hline & & 3 & 8.58 & 1.60 & 0.64 & 0.34 & 5.91 & 1.10 & 0.44 & 0.23 & 3.98 & 0.64 & 0.67 & 0.35 \\
\hline & & 6 & 9.91 & 2.06 & 0.76 & 0.39 & 6.82 & 1.42 & 0.52 & 0.27 & 4.60 & 0.83 & 0.80 & 0.40 \\
\hline & & 9 & 9.93 & 2.11 & 0.52 & 0.14 & 6.83 & 1.45 & 0.36 & 0.10 & 4.61 & 0.85 & 0.55 & 0.14 \\
\hline
\end{tabular}

It is worth noting that increasing the wetness rate $W R(1 / h)$ produces a drop in $\mathrm{F}_{3}$ and $\mathrm{F}_{4}$ and an increase in $F_{1}$ and $F_{2}$. For example, when ESDD $=0.2 \mathrm{mg} / \mathrm{cm}^{2}, \mathrm{NSDD}=0.6 \mathrm{mg} / \mathrm{cm}^{2}$, and $\mathrm{F}_{\mathrm{T} / \mathrm{B}}=1 / 1, \mathrm{~F}_{1}$ rises by $14.6 \%$ and $16.8 \%$, respectively, when the WR increases from 3 to 6 and $9 \mathrm{l} / \mathrm{h}$. In contrast, when the WR is increased from 3 to 6 and $91 / \mathrm{h}$, the $\mathrm{F}_{3}$ decreases by 9.3 percent and 15.7 percent, respectively.

Figure $9 \mathrm{c}$ demonstrates the connection between the suggested indices $\mathrm{F}_{1}-\mathrm{F}_{4}$ and $\mathrm{F}_{\mathrm{T} / \mathrm{B}}$ for polluted polymer insulators with $\mathrm{ESDD}=0.15 \mathrm{mg} / \mathrm{cm}^{2}, \mathrm{NSDD}=0.9 \mathrm{mg} / \mathrm{cm}^{2}$, and $\mathrm{WR}=9 \mathrm{l} / \mathrm{h}$. It can be seen that increasing the $\mathrm{F}_{\mathrm{T} / \mathrm{B}}$ produces a drop in the $\mathrm{F}_{1}$ and $\mathrm{F}_{2}$ while increasing the $\mathrm{F}_{3}$ and $\mathrm{F}_{4}$. This suggests that insulation under uniform pollution levels is more severe than under non-uniform pollution situations.

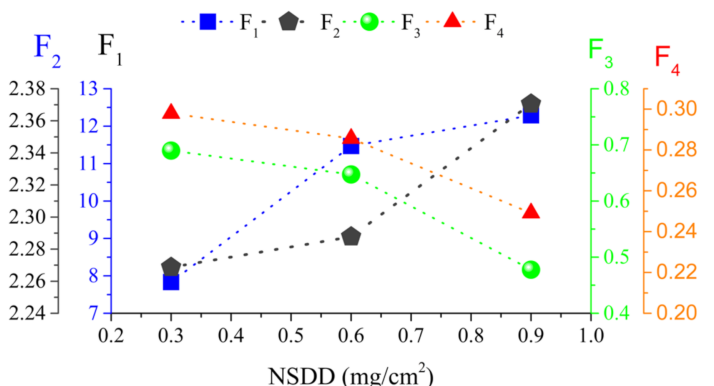

(a)

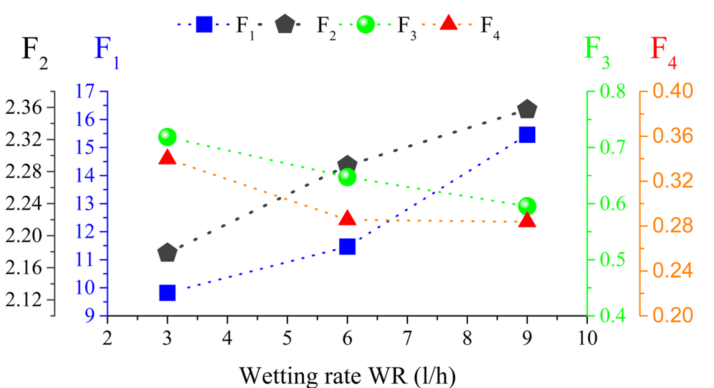

(b)

Figure 9. Cont. 


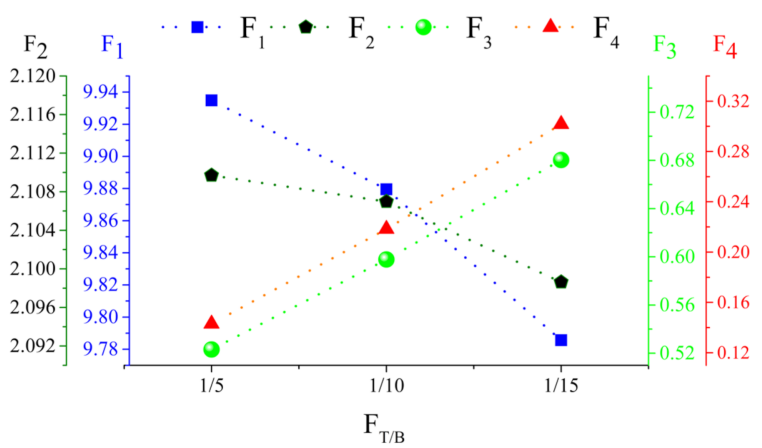

(c)

Figure 9. The indicator trends with (a) NSDD, (b) wetting rate (WR), and (c) $\mathrm{F}_{\mathrm{T} / \mathrm{B}}$.

\subsection{Insulator Condition Based on Indices Ranges Based on the Test Data}

In this part, the insulator condition was characterized based on the range of the indicators recovered experimentally that correlate to the levels of ESDD, NSDD, WR, and $\mathrm{FT} / \mathrm{B}$. The experimental results show that the $\mathrm{F}_{1}$ and $\mathrm{F}_{2}$ rise when increasing the ESDD, NSDD, and WR and decreasing $\mathrm{F}_{\mathrm{T} / \mathrm{B}}$. In contrast, the indices $\mathrm{F}_{3}$ and $\mathrm{F}_{4}$ drop when the ESDD, NSDD, and WR increase and $\mathrm{F}_{\mathrm{T} / \mathrm{B}}$ decreases. The proposed indicator ranges were estimated using classification tree methods. As an example, Figure 10 depicts the decision boundaries and trained decision tree for indicator $\mathrm{F}_{2}$. Table 5 shows the insulator condition prediction based on the indicator's values extracted experimentally. Accordingly, Tables 4 and 5 demonstrate that:

(1) In the clean and light pollution scenarios, the suggested indicator values were observed in the normal range, with a WR less than $3.81 / \mathrm{h}$ and an NSDD less than $0.45 \mathrm{mg} / \mathrm{cm}^{2}$. The probability of a discharge occurring in this scenario is almost non-existent.

(2) The insulator was in abnormal condition under light pollution $\left(0.05 \mathrm{mg} / \mathrm{cm}^{2}\right)$ with a high WR $(9 \mathrm{l} / \mathrm{h})$ and moderate and heavy levels of NSDD $\left(0.6\right.$ and $\left.0.9 \mathrm{mg} / \mathrm{cm}^{2}\right)$ for all contaminated distribution FT/B except the $1 / 5$ level, according to the ranges of indicators in Table 5. Furthermore, in the presence of medium contamination $\left(0.12 \mathrm{mg} / \mathrm{cm}^{2}\right)$, medium WR $(6 \mathrm{l} / \mathrm{h}), \operatorname{NSDD}\left(0.6 \mathrm{mg} / \mathrm{cm}^{2}\right)$, and FT/B $(1 / 1$ to $1 / 5)$, the insulator under investigation showed an abnormal state. Except in situations of high wetting, in which the probability of flashover increases, the probability of a discharge happening in these conditions is limited.



(a)

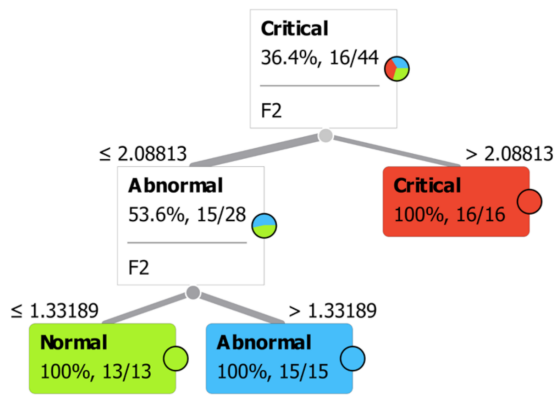

(b)

Figure 10. (a) Boundary detection of indicator $2 \mathrm{~F}_{2}$ (as an example); (b) classification tree for $\mathrm{F}_{2}$ indicator to estimate the insulator condition. 
Table 5. Insulator condition dependent on experimentally determined indices values.

\begin{tabular}{cccc}
\hline Indicator & Normal Range & Abnormal Range & Critical Range \\
\hline $\mathrm{F}_{1}$ & $<1.36$ & $>1.5$ and $<5.5$ & $>5.5$ \\
$\mathrm{~F}_{2}$ & $<1.33$ & $>1.33$ and $<2.1$ & $>2.1$ \\
$\mathrm{~F}_{3}$ & $>3.4$ & $>1.5$ and $<3.4$ & $<1.5$ \\
$\mathrm{~F}_{4}$ & $>2.2$ & $>1.2$ and $<2.2$ & $<1.2$ \\
\hline
\end{tabular}

(1) The critical condition of the insulator under testing was discovered in two states: first, under moderate pollution levels for WR $(91 / \mathrm{h}), \operatorname{NSDD}\left(0.9 \mathrm{mg} / \mathrm{cm}^{2}\right)$, and all pollution distribution categories; and second, under heavy pollution conditions for WR, NSDD, and all pollution distribution scenarios. In these conditions, the probability of a discharge occurring is significant, especially under severe wetting and heavy NSDD.

(2) The pre-flashover metric values of the indices indicate that these metrics can be employed to detect the flashover occurrence for polluted insulators during service.

\section{Determination of Indices Performance}

The performance of the suggested indicators to accurately estimate the insulator state from the 196 test observations was investigated. The confusion matrix illustrated in Figure 11 was used to compute the sensitivity and accuracy of these indices. The values of the confusion matrix were determined based on the capability of the insulator indicator to predict the correct condition. The selection of test results and recommended indices are specified as follows:

A: The results of the test and the indicator prediction are both positive (correct).

$\mathrm{B}$ : The test result is positive, but the indicator prediction is negative.

C: The test result is negative, but the indicator prediction is positive.

$\mathrm{D}$ : The results of the test and the indicator prediction are both negative (incorrect).

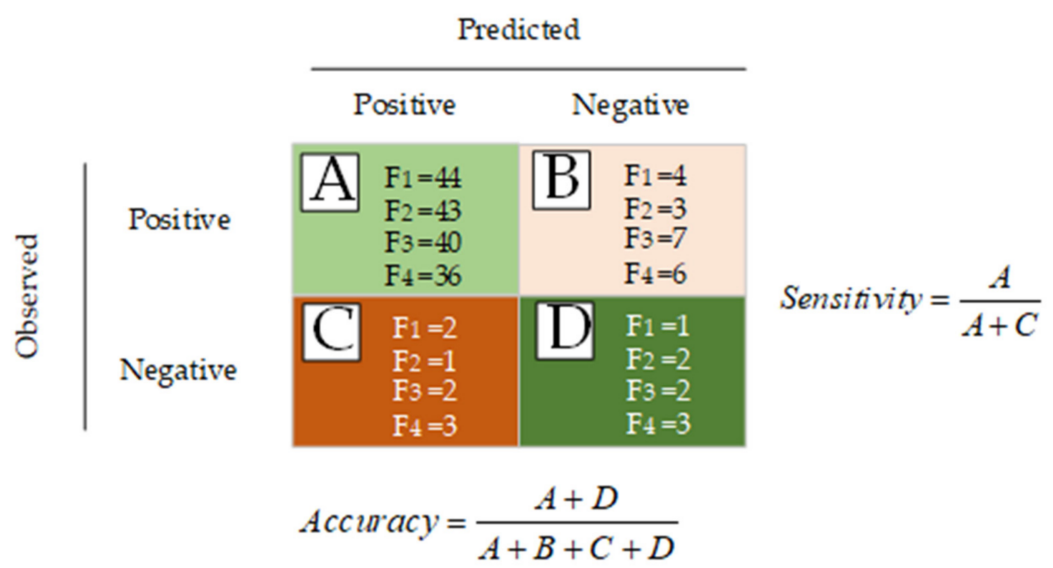

Figure 11. Confusion matrix for determining indices' sensitivity, specificity, and accuracy.

The insulator condition was successfully reflected in the majority of tests (170 out of 196). In contrast, 26 of the test findings were negative. The erroneous test findings might be related to a lack of adequate implementation of contaminants on the insulator surface, a measurement equipment mistake, or other factors.

The diversity in the number of projected outcomes may help determine which indicators are the best, with the indices with the greatest number of correct predicted outcomes being the best. In other words, the indices with the greatest number of correctly predicted results will be the most accurate. Based on the indices' prediction results presented in the figure above, indicator $F_{1}(44)$ had the highest number of correct predictions, followed by $F_{2}(43), F_{3}(40)$, and $F_{4}(36)$. The indicator measures (sensitivity and accuracy) were calculated as shown in Figure 12. Figure 12 shows that indicator $F_{2}$ has the highest sensitivity and accuracy, followed by $\mathrm{F}_{1}, \mathrm{~F}_{3}$, and $\mathrm{F}_{4}$, respectively. 

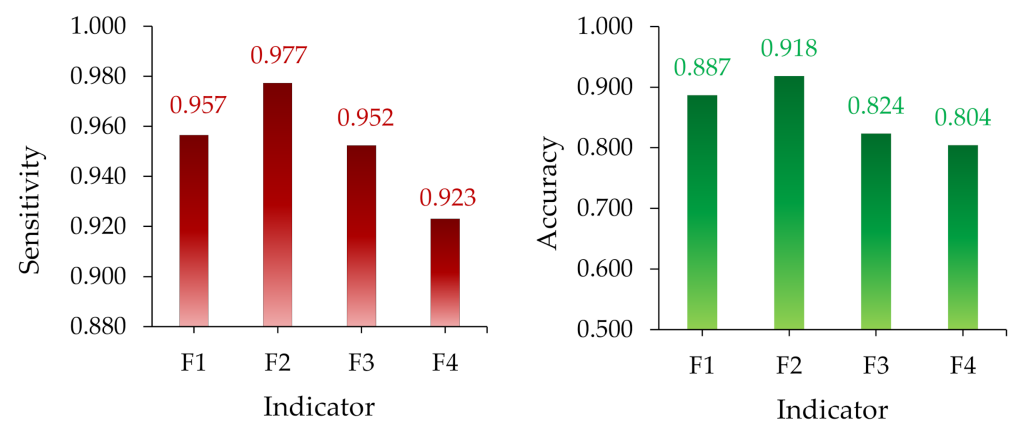

Figure 12. The value of the indices' sensitivity, specificity, and accuracy for evaluating the insulator condition.

\section{Conclusions}

Based on laboratory investigations conducted according to the IEC 60507 standard for polymer insulators under pollution, the leakage current has been measured. The leakage current value shows a positive slope when the ESDD, WR, and NSDD on the surface of insulators increase. However, the slope will be negative when $\mathrm{F}_{\mathrm{T} / \mathrm{B}}$ increases. The $\mathrm{LC}$ value is mostly affected by the pollution level, ESDD, and wetness rate, WR. Four indicators have been extracted from leakage current signals at different pollution levels. The results show that the suggested indicators are able to evaluate the insulator condition effectively. The indicators $F_{1}$ and $F_{2}$ indicate that the insulators will be in critical condition if their values exceed $5.5 \mathrm{~mA}$ and 2.1, respectively. If the $\mathrm{F}_{3}$ and $\mathrm{F}_{4}$ values are less than 1.5 and 1.2, respectively, the insulator will also be in the critical state. The possibility of flashover occurrence becomes higher when the insulator condition becomes critical. Moreover, the results show that all indicators presented in this study are useful for determining the condition of polluted insulators. However, based on the confusion matrix analysis, the indicator $\mathrm{F}_{2}$ performs better compared to other indicators. The current analysis can therefore be utilized to devise a reasonable criterion in identifying changes in the leakage current characteristics. When the measured leakage current reaches a particular threshold value, the associated change can be better identified. The suggested approach can be implemented online and a prototype device for monitoring the insulator condition can be developed in the future to verify the practicality of the suggested approach.

Author Contributions: Conceptualization, A.A.S., A.M.A.-S. and K.Y.L.; methodology, A.A.S., N.M. and Z.A.-M.; software, A.A.S., N.M., A.A.A.-S. and H.M.H.F.; validation, A.A.S., K.Y.L., Z.A.-M. and A.M.A.-S.; formal analysis, A.A.S. and N.M.; investigation, K.Y.L. and Z.A.-M.; resources, A.A.S. and A.M.A.-S.; data curation, A.A.S., A.M.A.-S., Z.A.-M. and K.Y.L.; writing-original draft preparation, A.A.S. and K.Y.L.; writing-review and editing, A.A.S., K.Y.L., Z.A.-M., A.M.A.-S., N.M., H.M.H.F. and A.M.A.-S.; visualization, A.A.S. and A.M.A.-S.; supervision, A.A.S., Z.A.-M. and K.Y.L.; project administration, A.A.S., K.Y.L., Z.A.-M. and A.M.A.-S.; funding acquisition, A.A.S., K.Y.L., Z.A.-M. and A.M.A.-S. All authors have read and agreed to the published version of the manuscript.

Funding: King Saud University, Riyadh, Saudi Arabia under Researchers Supporting Project number (RSP-2021/337).

Institutional Review Board Statement: Not applicable.

Informed Consent Statement: Not applicable.

Data Availability Statement: Not applicable.

Acknowledgments: The authors would like to acknowledge the Post-Doctoral Fellowship Scheme under the Professional Development Research University Grant (05E68) from Universiti Teknologi Malaysia (UTM) and the Researchers Supporting Project number (RSP-2021/337), King Saud University, Riyadh, Saudi Arabia.

Conflicts of Interest: The authors declare no conflict of interest. 


\section{References}

1. Sopelsa Neto, N.F.; Stefenon, S.F.; Meyer, L.H.; Bruns, R.; Nied, A.; Seman, L.O.; Gonzalez, G.V.; Leithardt, V.R.Q.; Yow, K.-C. A Study of Multilayer Perceptron Networks Applied to Classification of Ceramic Insulators Using Ultrasound. Appl. Sci. 2021, 11, 1592. [CrossRef]

2. Zhang, D.; Xu, H.; Liu, J.; Yang, C.; Huang, X.; Zhang, Z.; Jiang, X. Research on the Non-Contact Pollution Monitoring Method of Composite Insulator Based on Space Electric Field. Energies 2021, 14, 2116. [CrossRef]

3. Lan, L.; Mu, L.; Yuan, X.; Yan, J.; Wang, Y.; Wang, W.; Shen, Y.; Hao, L. Studies on metallurgical contamination accumulation characteristics on ceramic insulator of $500 \mathrm{kV}$ AC transmission line. IET Sci. Meas. Technol. 2019, 13, 722-728. [CrossRef]

4. Salem, A.A.; Abd-Rahman, R.; Al-Gailani, S.A.; Salam, Z.; Kamarudin, M.S.; Zainuddin, H.; Yousof, M.F.M. Risk Assessment of Polluted Glass Insulator Using Leakage Current Index Under Different Operating Conditions. IEEE Access 2020, 8, 175827-175839. [CrossRef]

5. Zhang, Z.; Yang, S.; Jiang, X.; Qiao, X.; Xiang, Y.; Zhang, D. DC Flashover Dynamic Model of Post Insulator under Non-Uniform Pollution between Windward and Leeward Sides. Energies 2019, 12, 2345. [CrossRef]

6. Mestriner, D.; Brignone, M. Corona Effect Influence on the Lightning Performance of Overhead Distribution Lines. Appl. Sci. 2020, 10, 4902. [CrossRef]

7. Yamashita, T.; Ishimoto, R.; Furusato, T. Influence of series resistance on dry-band discharge characteristics on wet pollute insulators. IEEE Trans. Dielectr. Electr. Insul. 2018, 25, 154-161. [CrossRef]

8. Ren, A.; Liu, H.; Wei, J.; Li, Q. Natural Contamination and Surface Flashover on Silicone Rubber Surface under Haze-Fog Environment. Energies 2017, 10, 1580. [CrossRef]

9. De Barros Bezerra, J.M.; Lima, A.M.N.; Deep, G.S.; da Costa, E.G. An Evaluation of Alternative Techniques for Monitoring Insulator Pollution. IEEE Trans. Power Deliv. 2009, 24, 1773-1780. [CrossRef]

10. Choi, I.H.; Koo, J.B.; Woo, J.W.; Son, J.A.; Bae, D.Y.; Yoon, Y.G.; Oh, T.K. Damage Evaluation of Porcelain Insulators with 154 kV Transmission Lines by Various Support Vector Machine (SVM) and Ensemble Methods Using Frequency Response Data. Appl. Sci. 2020, 10, 84. [CrossRef]

11. Suda, T. Frequency Characteristics of Leakage Current Waveforms of Artificially Polluted Suspension insulators. IEEE Trans. Dielectr. Electr. Insul. 2005, 8, 705-709. [CrossRef]

12. Hussain, M.M.; Farokhi, S.; McMeekin, S.G.; Farzaneh, M. Risk Assessment of Failure of Outdoor High Voltage Polluted Insulators under Combined Stresses Near Shoreline. Energies 2017, 10, 1661. [CrossRef]

13. Fofana, I.; N'cho, J.S.; Betie, A.; Hounton, E.; Meghnefi, F.; Yapi, K.M.L. Lessons to Learn from Post-Installation Pollution Levels Assessment of Some Distribution Insulators. Energies 2020, 13, 4064. [CrossRef]

14. Chen, W.; Wang, W.; Xia, Q.; Luo, B.; Li, L. Insulator Contamination Forecasting Based on Fractal Analysis of Leakage Current. Energies 2012, 5, 2594-2607. [CrossRef]

15. Salem, A.A.; Abd-Rahman, R.; Al-Gailani, S.A.; Kamarudin, M.S.; Ahmad, H.; Salam, Z. The Leakage Current Components as a Diagnostic Tool to Estimate Contamination Level on High Voltage Insulators. IEEE Access 2020, 8, 92514-92528. [CrossRef]

16. Jiang, Y.; McMeekin, S.G.; Reid, A.J.; Nekahi, A.; Judd, M.D.; Wilson, A. Monitoring contamination level on insulator materials under dry condition with a microwave reflectometer. IEEE Trans. Dielectr. Electr. Insul. 2016, 23, 1427-1434. [CrossRef]

17. Fontana, E.; Martins-Filho, J.F.; Oliveira, S.C.; Cavalcanti, F.J.M.M.; Lima, R.A.; Cavalcanti, G.O.; Prata, T.L.; Lima, R.B. Sensor network for monitoring the state of pollution of high-voltage insulators via satellite. IEEE Trans. Power Deliv. 2012, 27, 953-962. [CrossRef]

18. Douar, M.A.; Mekhaldi, A.; Bouzidi, M.C. Flashover process and frequency analysis of the leakage current on insulator model under non-uniform pollution conditions. IEEE Trans. Dielectr. Electr. Insul. 2010, 17, 1284-1297. [CrossRef]

19. Faramarzi Palangar, M.; Mirzaie, M. Diagnosis Porcelain and Glass Insulators Conditions Using Phase Angle Index Based on Experimental Test. IEEE Trans. Dielectr. Electr. Insul. 2016, 23, 3-9.

20. Shaik, M.G.; Karuppaiyan, V. Investigation of Surface Degradation of Aged High Temperature Vulcanized (HTV) Silicone Rubber Insulators. Energies 2019, 12, 3769. [CrossRef]

21. Zhao, S.; Jiang, X.; Zhang, Z.; Hu, J.; Shu, L. Flashover voltage prediction of composite insulators based on the characteristics of leakage current. IEEE Trans. Power Deliv. 2013, 28, 1699-1708. [CrossRef]

22. Terrab, H.; Bayadi, A. Experimental Study Using Design of Experiment of Pollution Layer Effect on Insulator Performance Taking into Account the Presence of Dry Bands. IEEE Trans. Dielectr. Electr. Insul. 2014, 21, 2486-2495. [CrossRef]

23. Liu, Y.; Du, B.X. Recurrent plot analysis of leakage current on flashover performance of rime-iced composite insulator. IEEE Trans. Dielectr. Electr. Insul. 2010, 17, 465-472. [CrossRef]

24. Li, J.; Sima, W.; Sun, C.; Sebo, S.A. Use of leakage currents of insulators to determine the stage characteristics of the flashover process and contamination level prediction. IEEE Trans. Dielectr. Electr. Insul 2010, 17, 490-501. [CrossRef]

25. Ghosh, R.; Chatterjee, B.; Chakravorti, S. A novel leakage current index for the field monitoring of overhead insulators under harmonic voltage. IEEE Trans. Ind. Electron. 2018, 65, 1568-1576. [CrossRef]

26. Fahimi, N.; Sezavar, H.R.; Abbas, A. Dynamic modeling of flashover of polymer insulators under polluted conditions based on HGA-PSO algorithm. Electr. Power Syst. Res. 2022, 205, 107728. [CrossRef] 
27. Sit, K.; Das, A.K.; Mukherjee, D.; Haque, N.; Deb, S.; Pradhan, A.K.; Dalai, S.; Chatterjee, B. Condition Monitoring of Overhead Polymeric Insulators Employing Hyperbolic Window Stockwell Transform of Surface Leakage Current Signals. IEEE Sens. J. 2021, 21, 10957-10964. [CrossRef]

28. Kordkheili, H.H.; Abravesh, H.; Tabasi, M.; Dakhem, M.; Abravesh, M.M. Determining the probability of flashover occurrence in composite insulators by using leakage current harmonic components. IEEE Trans. Dielectr. Electr. Insul. 2010, 17, 502-512. [CrossRef]

29. IEC 507. Artificial pollution tests on high-voltage insulators to be used on A.C. systems. Int. Stand 1991, 2, 1-7.

30. Salem, A.A.; Abd-Rahman, R.; Kamarudin, M.S.; Ahmad, H.; Jamail, N.A.M.; Othman, N.A.; Ishak, M.T.; Baharom, M.N.R.; Al-Ameri, S. Proposal of a Dynamic Numerical Approach in Predicting Flashover Critical Voltage. Int. J. Power Electron. Drive Syst. (IJEPDS) 2019, 10, 602-610. [CrossRef]

31. Salem, A.A.; Abd-Rahman, R.; Rahiman, W.; Al-Gailani, S.A.; Al-Ameri, S.M.; Ishak, M.T.; Sheikh, U.U. Pollution Flashover Under Different Contamination Profiles on High Voltage Insulator: Numerical and Experiment Investigation. IEEE Access 2021, 9 , 37800-37812. [CrossRef]

32. Ahmad, J.; Tahir, A.; Stewart, B.G.; Nekahi, A. Forecasting Flashover Parameters of Polymeric Insulators under Contaminated Conditions Using the Machine Learning Technique. Energies 2020, 13, 3889.

33. Salem, A.A.; Abd-Rahman, R.; Ahmad, H.; Kamarudin, M.S.; Jamal, N.A.M.; Othman, N.A.; Ishak, M.T. A New Flashover Prediction on Outdoor Polluted Insulator Using Leakage Current Harmonic Components. In Proceedings of the 2018 IEEE 7th International Conference on Power and Energy (PECon), Kuala Lumpur, Malaysia, 3-4 December 2018; pp. 413-418.

34. Zhang, Z.; Qiao, X.; Yang, S.; Jiang, X. Non-Uniform Distribution of Contamination on Composite Insulators in HVDC Transmission Lines. Appl. Sci. 2018, 8, 1962. [CrossRef]

35. Aydogan, A.; Atalar, F.; Ersoy Yilmaz, A.; Rozga, P. Using the Method of Harmonic Distortion Analysis in Partial Discharge Assessment in Mineral Oil in a Non-Uniform Electric Field. Energies 2020, 13, 4830. [CrossRef]

36. Fielding, A.H.; Bell, J.F. A review of methods for the assessment of prediction errors in conservation presence/absence models. Environ. Conserv. 1997, 24, 38-49. [CrossRef] 